\title{
A EXPERIÊNCIA DE ENSINO DE PAISAGISMO NA FACULDADE DE ENGENHARIA, ARQUITETURA E URBANISMO DA UNIVAP
}

\author{
THE LANDSCAPE TEACHING EXPERIENCE IN THE ENGINEER, ARCHITECTURE AND \\ URBANISM COLLEGE OF UNIVAP.
}

\section{SANTOS, Emmanuel Antonio dos}

Prof. Dr. - UNIVAP, ITA.E-mail: emmanuel_santos@uol.com.br

\section{RESUMO}

A experiência de ensino em paisagismo em escolas particulares de arquitetura e urbanismo, o desenvolvimento e alocação das disciplinas na grade curricular, o papel do paisagismo na formação do arquiteto e urbanista, os exercícios e processos de desenvolvimento de projeto, o aporte conceitual, teórico e metodológico. Contribuição a constituição de currículos e exercícios para o ensino de paisagismo.

Palavras-chave: Ensino, paisagismo, currículo.

\begin{abstract}
The landscape teaching experience in architecture and urbanism schools, the development and location of the disciplines on de curriculum, the roll of the landscape subject on the graduate studies of the architects, the exercises and processes of developing the designs and the conceptual and theoretical methodological schemes. The contributions to constitute architecture college curriculums and practice exercises to the landscape teaching
\end{abstract}

Key words: Teaching, landscape, curriculum.

A nossa experiência no ensino de paisagismo na faculdade de Engenharia, Arquitetura e Urbanismo da UNIVAP, Universidade do Vale do Paraíba em São José dos Campos, inicia-se em 1983, quando, segundo a grade curricular então em vigor, a disciplina comparecia na 4 série, com o papel de introduzir o aluno na prática de proposição de projetos de paisagismo. A disciplina desenvolvia-se por meio da elaboração de exercícios práticos de projetação em atelier, em que eram solicitados aos alunos o desenvolvimento de leitura, análise, diagnóstico, prognóstico e proposição para três escalas de projeto, como segue: em nível de plano paisagístico na abrangência do município, procurando sempre a sua inserção no âmbito da região de estudo; em nível de ante projeto paisagístico na elaboração de um sistema de espaços públicos livres verdes coletivos urbanos, em que a idéia de parque preponderava e em nível de projeto de plantação na elaboração de projeto de paisagismo para as áreas livres no entorno imediato da edificação, e em alguns casos no âmbito do espaço público de vizinhança, a praça.

Apesar, da sua distribuição/alocação em um único ano letivo contando com 04 horas/aula semanais, é de se imaginar o imenso esforço, que o desenvolvimento de uma disciplina com escopo tão abrangente e diverso requer, aliado as dificuldades de sua condução por um único docente. Comprometia-se desse modo, em parte, o pleno desenvolvimento dos exercícios e não se fazia possível, também, quaisquer oportunidades de integração interdisciplinar, ainda que houvesse por parte, tanto dos alunos como dos responsáveis por outras disciplinas, em especial as de projeto do edifício essa solicitação freqüente e enfática.

Cabe destacar que, essa solicitação enfática das disciplinas de projeto do edifício, referia-se a elaboração do projeto do jardim do entorno imediato da edificação com preponderância na escolha de vegetação para efeito ornamental, onde se entendia o paisagismo como com- 
plementar ao edifício previamente projetado. As disciplinas de planejamento urbano, por seu lado, solicitavam o projeto de parques e áreas verdes, onde a ênfase recaía sobre os espaços vegetados programados para as atividades de lazer ativo, geralmente parques esportivos e afins. Entendia-se desse modo que a contribuição e papel da disciplina de paisagismo no curso e na formação do arquiteto estavam restritas ao projeto do jardim com valor e papel ornamental com a intenção não claramente expressa de emoldurar os objetos arquitetônicos, assim como no âmbito da cidade, restaria ao paisagismo projetar as áreas verdes, geralmente tomadas como parques, sem a compreensão da possibilidade de discutir a constituição de um sistema de espaços livres como contribuição ao desenho da/na cidade.

Apesar dessas dificuldades apontadas, procurava-se garantir um mínimo de conteúdos por meio de seminários, visitas técnicas a situações de especial interesse paisagístico, leituras programadas e uma forte presença do exercício de "projetação" em atelier. Dessa maneira, procurava-se fomentar no aluno a ampliação da sua compreensão da paisagem e do paisagismo para além do jardim e das áreas verdes, sem com isso relegar essas duas instâncias a um plano de menor relevância o que se pretendeu foi permitir apreensão não reducionista.

A gradativa percepção da sua importância no curso revelava-se nas respostas positivas dos alunos, em seu envolvimento na condução das propostas e, principalmente em sua solicitação por maior presença da disciplina na grade curricular, seja em maior número de horas, seja na implantação de novas disciplinas da área.

Cabe destacar que, atuávamos como docente concomitantemente, em outras duas universidades, no curso de Arquitetura e Urbanismo da Universidade Braz Cubas em Mogi das Cruzes' ${ }^{1}$, assim como, também, no curso de Arquitetura e Urbanismo da Universidade de Taubaté, onde desenvolvíamos, também, a implantação das disciplinas de paisagismo em seus conteúdos e distribuição serial segundo as possibilidades de inserção conforme a grade curricular de cada curso.

No caso da Universidade de Taubaté, era o momento de revisão geral das ementas das disciplinas, e também se abria a oportunidade de ampliação de seu espaço na grade curricular. Propusemos, então, em face das condições e atmosfera favoráveis, uma distribuição serial, em que viemos a contar com 03 (três) disciplinas anuais, cada qual abrangendo uma escala e conteúdos específicos: a do lugar ou entorno imediato da edificação; a do espaço público, a praça e/ou parque urbanos e a do planejamento da paisagem ou paisagem regional. Essa estrutura e distribuição serial eram então, similares àquela que implantávamos na Braz Cubas, diferenciava-se por contar, nesta última, com carga horária semestral, enquanto que na UNITAU contávamos com carga horária anual.

A peculiaridade relativa a diversidade dos campos de estudo, os tecidos agregados de Taubaté, Tremembé e Pindamonhangaba, no caso da UNITAU, e a região metropolitana de São Paulo, no caso da UBC, apesar da complexidade inerente em conduzir estudos e propostas em situações aparentemente tão díspares, contribuiu de forma muito significativa, para a constituição de um arcabouço de experiências comparativas, em que se pôde constantemente promover revisões e adequações.

No primeiro caso, na UNITAU, os aspectos do suporte com aparência menos processado conduziam o estudo e as proposições para a compreensão da paisagem em sua inserção regional, no sentido de procurar formas e alternativas de crescimento e desenho urbano e da urbanização, onde as situações com especial fragilidade como as várzeas e as encostas, deveriam ser consideradas mais como atributo do que como óbices. Procurava-se também aprofundar a investigação, por meio dos exercícios de projeto, em direção a constituição de um sistema de espaços livres intra e interurbanos como estratégia para garantir uma distribuição mais equilibrada de espaços vegetados, de lazer, de conservação e de beleza cênica. 
No caso da UBC, o cenário de complexidade da veloz ampliação dos tecidos urbanos da região metropolitana por sobre áreas de produção agrícola da região leste, especialmente hortifrutigranjeiros, conduziam os estudos em direção a compreensão do avanço da urbanização e das estratégias de projeto para garantir paisagens aonde não se viesse a perder de modo irreversível o recurso solo fértil onde o seu processamento, apesar de intenso, guarda ainda situações de beleza cênica inerentes a essas áreas.

Nos dois casos, lacunas apareciam em relação aos conteúdos inicialmente pensados para as disciplinas. Percebíamos a fragilidade, com as informações então disponíveis, em dar conta da apreensão dos processos de transformação geomorfológicas das situações estudadas, apoiávamo-nos ainda em bases cartográficas muito antigas, desatualizadas e em alguns casos inexistentes. Na UNITAU e posteriormente na UNIVAP, a inserção de disciplinas de geoprocessamento e sensoriamento remoto na grade curricular dos cursos de graduação, mesmo que com carga horária restrita e distribuição serial nem sempre adequada, aparecendo logo no segundo ano do curso, sem conexão alguma com as disciplinas de paisagismo, as quais aparecem apenas a partir do terceiro ou quarto anos, é de grande contribuição para o estudo do que se convencionou denominar características do meio físico. Podendo-se contar inclusive com imagens mais atualizadas e com maior grau de controle da informação. Essa "ferramenta" de apoio às análises pode e de fato assim o faz facilitar em muito a percepção dos alunos dos vários elementos presentes na estrutura das paisagens.

Por outro lado, a partir dos resultados positivos obtidos com o tipo de distribuição serial e da carga horária disponível nos dois casos acima citados, além da inserção das disciplinas de apoio a leitura do meio físico, confirmava-se ainda mais a necessidade de ampliação e readequação da distribuição das disciplinas de paisagismo na UNIVAP, tanto para atender as possibilidades de exercícios de projetos que se anunciavam com o uso de meios mais precisos e sofisticados de leitura e diagnose, como pela crescente solicitação da elaboração de exercícios acadêmicos que incluíssem diversas e múltiplas escalas de abordagem, aliados a preocupação com a proteção dos recursos naturais como sinônimos de preservação ambiental, especialmente daquelas disciplinas de planejamento urbano.

Com o decorrer dos anos víamos também, na UNIVAP, a crescente demanda por conteúdos de paisagismo, tanto nas solicitações de propostas de trabalhos finais de graduação, quanto nas cada vez mais freqüentes solicitações de integração, especialmente em atelier de projeto do edifício e de planejamento urbano. É importante destacar também que, gradativamente, essas solicitações foram saindo do âmbito dos docentes e se configurando cada vez mais como demanda dos próprios alunos.

Desse modo, abria-se espaço para a discussão da possibilidade de inserção de novas disciplinas e/ou acréscimo na alocação de carga horária naquelas existentes, a fim de suprir as crescentes solicitações que se apresentavam.

É assim que, depois de idas e vindas na alocação e distribuição serial nas diversas experiências curriculares, firma-se a área de paisagismo em três semestres e três escalas correspondentes, quais sejam: História e Teoria do Paisagismo, no segundo semestre do terceiro ano; Projeto de paisagismo no primeiro semestre do quarto ano e Planejamento da paisagem no segundo semestre do quarto ano, além dos eventuais trabalhos de graduação.

Essa alocação e seriação da disciplina, por solicitação nossa, tem permitido que o aluno, já em fase profissionalizante do curso, exercite a integração disciplinar de modo mais consistente e consciente, fazendo link com as outras disciplinas e com o conhecimento adquirido até essa etapa do curso, resgatando e fazendo relações, logo de início na primeira disciplina de História e Teoria, entre o paisagismo e a história das cidades, da urbanização e da arquitetura. 
Nos anos mais recentes, a partir do início dos anos 2000, com a disciplina de estudos ambientais oferecida no primeiro ano da graduação, houve substancial acréscimo para os alunos na compreensão dos processos de apropriação do ambiente, da degradação e dos impactos na paisagem.

Assim como também, nos outros dois semestres subseqüentes, é comum relacionar os exercícios de paisagismo com os conceitos de ciências ambientais, topografia, desenho urbano, e planejamento apreendido nos primeiros semestres. Onde se procuram reafirmar conteúdos conceituais a partir da prática projetual, solicitando aos alunos na elaboração das propostas de projeto as justificativas e os aportes teóricos conceituais que fornecem sustentabilidade as suas propostas.

Apresentamos a seguir a ementa de cada uma das disciplinas, no sentido de explicitar os seus objetivos gerais, após o que comentamos os exercícios e as dificuldades e vantagens próprias a cada uma delas.

\section{Ementa das disciplinas}

Disciplina: $\quad$ História e Teoria do Paisagismo

Ano da graduação: $3^{\circ}$ - segundo semestre letivo

Carga Horária: 60 h/a

Ementa:

Introdução à paisagem: conceito de paisagem; conceito de paisagismo; paisagens significativas.

A evolução dos conceitos e das práticas profissionais: a Antigüidade Clássica; a Idade Média; o Renascimento; a Revolução Industrial; o período contemporâneo.

Paisagens: paisagem urbana; paisagem rural; espaços livres; os movimentos de parques e de embelezamento. $O$ movimentos de renovação urbana do pós guerras; o desenho urbano e a produção de espaços livres públicos coletivos urbanos.

A disciplina, em função de seu caráter teórico conceitual, não resulta em um exercício prático de projetação, o acompanhamento do aproveitamento e a avaliação dos alunos se fazem em seminários preparados pelos alunos a partir de temas/períodos históricos pré-selecionados, os quais devem permitir ao aluno um panorama da produção do paisagismo no Brasil e no mundo. Propõe-se ainda um exercício de representação gráfica de vegetação em planta, como oportunidade do aluno iniciar a prática de desenho de paisagismo, preparando-o para os próximos semestres.

Essa disciplina não tem o papel nem a pretensão de cobrir todos os aspectos da história do paisagismo no tempo e no espaço, pretende-se introduzir a percepção da paisagem e suas manifestações concretas no que se consideraram como momentos mais significativos / exemplares do paisagismo.

Ressente-se, para uma mais adequada compreensão dos processos de formação do pensamento e da prática do paisagismo, como suporte para formar arcabouço teórico conceitual que permita tomada de decisão de projeto consciente, a ser solicitado nos semestres subseqüentes, de maior aprofundamento. Pensa-se que uma maior alocação de horas para a disciplina pode em parte auxiliar em suprir essa lacuna, no entanto entende-se como bem vinda a contribuição consistente que uma integração efetiva com as disciplinas de História e Teoria da Arquitetura e do Urbanismo, somadas a disciplina de História da Arte e Estética em um ou mais seminários e exercícios elaborados pelos alunos sob supervisão e acompanhamento dos professores dessas disciplinas, resultando em um painel onde o conhecimento se apresentaria de modo integrado e integrador, contribuindo para a desfragmentação da percepção do ambiente no tempo e no espaço. 
Disciplina: $\quad$ Projeto de Arquitetura e Urbanismo VII - Paisagismo Intra - urbano Ano da graduação: $4^{\circ}$ - primeiro semestre letivo

Carga Horária: 60 h/a

Ementa:

Espaços livres no entorno imediato das edificações: as áreas remanescentes do uso e da ocupação do solo no âmbito e na escala urbana. O Projeto de paisagismo como oportunidade de qualificação dos espaços urbanos a partir da apropriação do lote. A utilização da vegetação e dos elementos de composição paisagística pelo arquiteto na elaboração dos projetos. $\bigcirc$ processo de elaboração de projetos de paisagismo: inventário; diagnóstico; prognóstico e projeto. Plano de massas, estudo preliminar, anteprojeto e projeto. Projetos de paisagens: espaço do entorno imediato da edificação e espaço público na escala da rua.

A disciplina de projeto de paisagismo no primeiro semestre do quarto ano, com caráter de exercício prático de projetação, desenvolve-se a partir do desenvolvimento de um projeto de paisagismo para espaço público livre coletivo urbano relacionado com o entorno imediato de uma edificação também de uso publico. $\bigcirc$ projeto desenvolve-se após uma série de exercícios de apropriação do lote/gleba pré selecionada em conjunto com a disciplina de projeto do edifício, somente com o uso da vegetação, onde o aluno inicia a compreensão do lote e da sua apropriação espacial a partir da configuração desejada para as áreas a permanecerem livres de edificação - projetar em "negativo". Ao final do semestre o aluno deve apresentar um ante projeto de paisagismo com a definição clara da vegetação e de todos os elementos de paisagem empregados.

Como a ênfase nesse semestre recai sobre o exercício de projeto de paisagismo no entorno imediato da edificação, a partir da integração com a disciplina de projeto do edifício, a qual solicita um projeto de edifício de grande porte para atividades recreativas e culturais, tem sido possível ampliar o escopo da proposta de modo a selecionar em conjunto pelas duas disciplinas, projeto e paisagismo, a área de intervenção, quanto a sua localização, porte, configuração e dimensionamento. Estrategicamente, com a estreita colaboração da disciplina de projeto do edifício, a escolha dessas áreas tem recaído sobre glebas com área nunca inferior a $25.000,00 \mathrm{~m} 2$, localizada preferencialmente em setores urbanos em expansão e/ou periferias em consolidação.

A integração entre as disciplinas se consubstancia desde a construção do programa de necessidades o qual é elaborado em conjunto, assim como durante a elaboração do projeto desde sua concepção inicial, como os estudos de massa, de implantação das soluções arquitetônicas para os espaços livres e para as edificações, para as áreas ajardinadas e dos equipamentos e mobiliário urbano.

Procura-se também no estudo de inserção dessas atividades nas glebas estudar e propor soluções de desenho urbano para além dos limites da gleba selecionada para estudo, dessa forma pensa-se como desejável a integração com outras duas disciplinas do mesmo ano/semestre, quais sejam Desenho Urbano e Planejamento Urbano, onde na primeiro delas, não parece seja necessário justificar, desde que há estreita relação entre métodos e técnicas de abordagem configurando-se como óbvia a necessidade de integração, no caso da disciplina de Planejamento Urbano, desde que é do seu escopo estudar e exercitar a aplicação dos instrumentos de gestão e política urbanos, hoje consolidados na lei conhecida com Estatuto da Cidade, seria muito interessante que os alunos pudessem com a integração interdisciplinar exercitar a sua aplicação na área estudada, onde se poderia garantir a efetiva incorporação das vantagens urbanísticas, paisagísticas e arquitetônicas advindas de operações de gestão urbana, possíveis a partir de um projeto do / no urbano, sem contudo deixar de projetar no intra-lote e no entorno imediato da edificação. 
Dado os resultados positivos até aqui alcançados com a integração entre as disciplinas de Projeto e de Paisagismo, percebe-se como plenamente exeqüível, e bem vinda pelos professores responsáveis por aquelas disciplinas, a integração interdisciplinar com Desenho Urbano e Planejamento Urbano. Nesse sentido pensa-se em propor, para os próximos semestres, exercícios de maior abrangência para que seja possível atender as demandas específicas próprias dos programas mínimos de cada disciplina, bem como de modo a permitir o desenvolvimento do exercício em consonância com os tempos próprios de cada uma delas.

Disciplina: $\quad$ Projeto de Arquitetura e Urbanismo VIII - Planejamento da paisagem Ano da graduação: $4^{\circ}$ - primeiro semestre letivo

Carga Horária: 60 h/a

Ementa:

Espaços livres públicos coletivos urbanos: Sistemas de Espaços Livres: áreas verdes; praças; parques e reservas, no âmbito e na escala do município, com ênfase no urbano.

O Planejamento da paisagem: os Recursos Naturais; a hidrografia; cobertura vegetal; clima; solos, como elementos de constituição das paisagens.

A utilização dos recursos naturais: produção; consumo; lazer; embelezamento; manutenção do ambiente.

O processo de planejamento paisagístico: inventário; diagnóstico; prognóstico e projeto.

Projetos de paisagens: Espaço público na escala do município, parque de âmbito regional.

$\mathrm{Na}$ disciplina de planejamento da paisagem, no segundo semestre do quarto ano, os alunos desenvolvem um projeto de parque com abrangência e âmbito regional, a partir do estudo e investigação das áreas ambientalmente frágeis existentes no município selecionado como estudo de caso. Geralmente essas áreas recaem sobre encostas e fundos de vale, frequentemente os alunos se interessam por situações de recomposição de mata ciliar e sistemas de lazer em áreas carentes e de baixa renda.

É nessa disciplina, em função da escala e dimensão das áreas de trabalho a utilização de imagens de satélite e em alguns casos técnicas de geoprocessamento para análise e avaliação das fragilidades e potencialidades dos sítios em estudo. Nota-se, contudo a carência de acompanhamento mais próximo dessa área de estudo nessa etapa do curso, onde a ausência de um acompanhamento por parte de um professor e integração interdisciplinar com sensoriamento remoto / geoprocessamento poderia suprir essa lacuna, tornando o resultado final, tanto mais consistente, quanto mais próximo de um padrão em nível profissional como se espera do aluno nessa fase do curso.

É comum, a partir dessas duas últimas disciplinas, os alunos se interessarem em desenvolver os seus trabalhos de graduação na área de paisagismo, adotando temas como praças, áreas verdes em setores urbanos, parques e sistemas de lazer e cultura com preponderância para os espaços livres.

As dificuldades mais prementes referem-se especialmente a pouca carga horária disponível para as disciplinas nos semestres em que estão alocadas, inclusive para o desenvolvimento de atividades em atelier com acompanhamento e orientação por parte do professor, as dificuldades em realizar visitas monitoradas, próprias de cursos das entidades particulares e especialmente no período noturno, assim como disponibilidade de docentes com formação específica na área.

Preocupa-nos a fragilidade e dificuldade em contar com a permanência do corpo docente na instituição, dado que em instituições particulares é muito difícil a fixação dos docentes, seja na disciplina, no curso ou até mesmo na instituição. Disso decorre solução de continuidade e constante retomada de processos por vezes já em adiantado estado de integração, fazendo 
com que seja necessário reiniciar práticas e experiências a partir do zero, perdendo-se corpo teórico e prático acumulado.

As respostas positivas dos alunos, assim como a crescente cooperação dos colegas professores da instituição especialmente os das áreas de projeto, planejamento, estudos ambientais e cartografia, têm contribuído muito para efetivarmos tanto a desejada integração interdisciplinar, como o desenvolvimento e consolidação da disciplina no curso de arquitetura e urbanismo.

Em um país com tamanha diversidade cultural, relativamente novo em sua constituição urbana, apesar de em processo acelerado e tardio, com tamanha diversidade de recursos, onde alguns destes já se mostram escassos e de acesso restrito, com muita dificuldade em se firmar como espaço dignamente construído, penso que o arquiteto deva contar em sua formação, com o aporte dos conhecimentos em paisagem e ambiente, que se pautem por uma integração inter, multi trans disciplinar, seja que nome ou forma tenha, para que seja possível formar verdadeira consciência crítica em relação aos processos de apropriação e construção dos espaços de assentamento humano que sejam ambientes de expressão plena da cidadania.

\section{Nota}

(1) Para maiores esclarecimentos e detalhamentos, ver artigo referente à experiência de ensino de Paisagismo na Universidade Braz Cubas, publicado em parceria com o Prof. Dr. Maria da Glória Lanci nos anais do IV ENEPEA. 
